\title{
Photonic Bandgap Fibers
}

\section{Barkou, Stig Eigil; Broeng, Jes; Bjarklev, Anders Overgaard}

\section{Published in:}

Conference Proceedings of LEOS' 99, Vol 2

Link to article, DOI:

10.1109/LEOS.1999.811878

Publication date:

1999

\section{Document Version}

Publisher's PDF, also known as Version of record

Link back to DTU Orbit

Citation (APA):

Barkou, S. E., Broeng, J., \& Bjarklev, A. O. (1999). Photonic Bandgap Fibers. In Conference Proceedings of LEOS'99, Vol 2 (pp. 615-616). IEEE. https://doi.org/10.1109/LEOS.1999.811878

\section{General rights}

Copyright and moral rights for the publications made accessible in the public portal are retained by the authors and/or other copyright owners and it is a condition of accessing publications that users recognise and abide by the legal requirements associated with these rights.

- Users may download and print one copy of any publication from the public portal for the purpose of private study or research.

- You may not further distribute the material or use it for any profit-making activity or commercial gain

- You may freely distribute the URL identifying the publication in the public portal

If you believe that this document breaches copyright please contact us providing details, and we will remove access to the work immediately and investigate your claim 


\author{
Photonic Bandgap Fibers \\ Stig E. Barkou, Jes Broeng, Anders Bjarklev \\ Research Center COM, Technical University of \\ Denmark, Building 348, DK-2800 Lyngby, Denmark \\ Telephone: +45 452538 00, Fax: +45 45931634 , \\ E-mail: seb@com:dtu.dk
}

Abstract: Photonic bandgap fibers are described using a new Kagomé cladding structure. These fibers may potentially guide light in low-index regions. Such fibers offer new dispersion properties, and large design flexibility.

Introduction: In 1987 Yablonovitch suggested that the electronic bandgaps in semiconductors might have an optical analogy, so-called photonic bandgaps (PBGs) [1], in periodic dielectric structures.

PBGs may appear in optical fibers ( $P B G$-fibers) with a large number of air holes, placed periodically in the transverse plane of the cladding structure [2]. The core may be introduced by breaking the periodicity of the air holes at the center of the fiber. For a given frequency, this may allow a degenerated mode to be confined in the core region, with a propagation constant, $\beta$, not allowed in the cladding structure due to a PBG [3]. It has now been demonstrated experimentally that this makes it possible to localize modes in the core region by the PBG effect [4].

The purpose of this paper is twofold: We will, for the first time, suggest using a two-dimensional Kagomé [5] lattice structure as cladding structure in PBG fibers. We will then use this design to describe some important basic qualities of PBG fibers.

Photonic bandgap fibers: The cladding structure of a PBG fiber is a periodic system of air holes in a matrix of undoped silica. Originally, it was suggested to place the air holes in a triangular lattice structure $[2,6]$. It is, however, easier to obtain PBGs, if the air holes are situated in a honeycomb lattice structure $[7,8,4]$. The last basic two-dimensional hexagonal lattice structure, the Kagomé structure [5], is here for the first time suggested as a possible cladding structure.

The basic design of a PBG fiber with a Kagomé cladding structure is shown in Fig 1 , which also defines the simple unit cell [9] of this structure. As with the honeycomb cladding structure, a number of large silica regions are present in this structure [7]. However, these large silica regions are slightly more isolated in the Kagomé structure. This makes it possible to obtain larger air filling fractions for a given air-hole size.

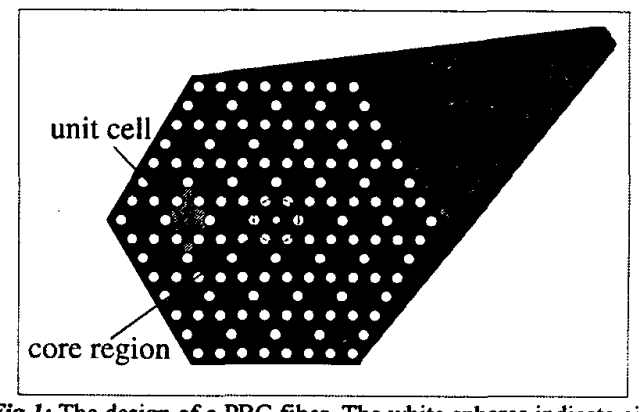

Fig 1: The design of a PBG fiber. The white spheres indicate air holes invariant along the length axis of the fiber. Here the cladding air holes are situated on a Kagome lattice. The extra air hole added at the center creates a core area, along which light is guided.

Notice the extra air hole at the center defining the core region (see Fig 1). This illustrates one of the most basic differences between PBG fibers and fibers relying on total internal reflection (TIR) as the guiding principle: PBG fibers may guide light in core regions with a lower refractive index than the average refractive index of the surrounding cladding structure. Therefore, PBG fibers may offer new gas and liquid detection schemes $[2,12]$. To understand, why PBG fibers may guide light in low-index regions, one must investigate the PBGs of the cladding in more detail. Fig 2 shows calculated results for a PBG fiber using the principal design shown in Fig 1. A supercell planewave method $[10,6]$ was employed, using 32768 plane waves and a supercell encompassing $4 * 4$ simple cells. The diameter of the cladding air holes is $0.55 \Lambda$, where $\Lambda$ is the distance between neighboring air-hole centers. The diameter of the core air hole is $0.4 \Lambda$. The refractive index of silica was chosen wavelength independent as 1.45 .

The curve at the top of Fig 2 shows the mode index $(\mathrm{n}=\mathrm{\beta} / \mathrm{k})$ of the fundamental space filling mode (FSM), as a function of the normalized wavelength, $\nu \Lambda$ ( $\lambda$ is the free space wavelength). FSM is the

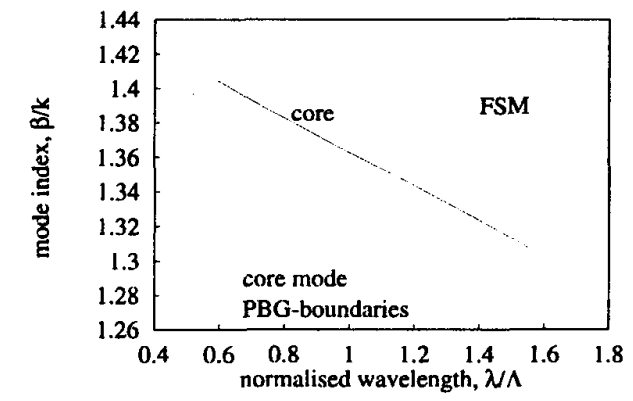

Fig 2: $\mathrm{PBGs}$ in the cladding structure appear below $\mathrm{n}_{\mathrm{FSM}}$. The core may, therefore, be a low-index core, yet guide light inside a PBG. 
extended field solution, with the largest $\beta$-value allowed in the cladding structure at a given frequency, and corresponds to the cladding index of a standard optical fiber. Any mode guided by total internal reflection would appear above $n_{\text {FSM }}$ in Fig 2. Notice that $n_{F S M}$ is strongly wavelength dependent. This is caused by the cladding modes avoiding the airholes at short wavelengths.

Fig 2 also indicates the boundaries of the two lowest-order PBGs in the cladding structure. Here, the forbidden $\beta$-intervals appear as forbidden mode index intervals below $\mathrm{n}_{\mathrm{FSM}}$. Any PBG guided mode must appear inside one of the PBG regions, since the guided mode has $\beta$-values not allowed in the cladding structure. If one could guide light inside a PBG with a mode index less than 1 , this would make it possible to guide light in vacuum!

The calculated guided mode solution of the present structure is also shown in Fig 2 . The guided mode is strongly confined spatially, when it has a mode index near the center of the PBG. The calculated localized core mode field solution is indicated in Fig 3, which corresponds to $\lambda \Lambda=1.2$ in Fig 2.

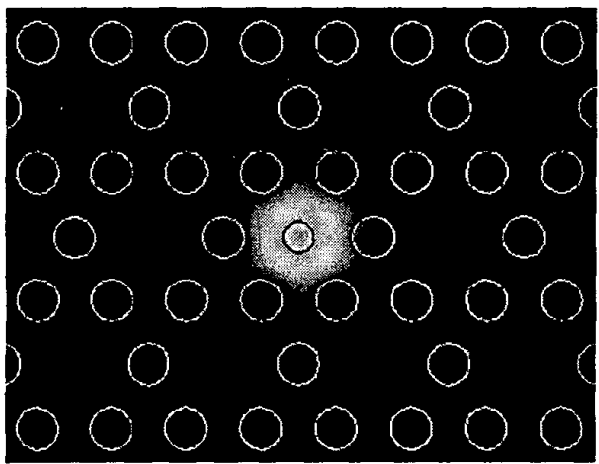

Fig 3: The electric field squared, for the guided mode indicated in Fig 2, at $\lambda \Lambda=1.2$. The circles indicate the air holes. The light is guided along the central air hole.

The group velocity dispersion, $G V D=-\frac{\lambda}{c} \frac{d^{2} n}{d \lambda^{2}}$ (c is the free-space velocity of light) of the core mode is typically positive and large when using the honeycomb cladding design [11], revealed as a clearly visible downward bending, in an index plot similar to Fig 2. In comparison, the downward bending of the core mode for $\lambda / \Lambda>1$ is hardly visible in Fig 2, corresponding to dispersion properties more similar to those of standard fibers. This indicates the possible use of the Kagomé PBG fiber to obtain flat, near-zero dispersion.

The flexible morphology possibilities in the design of the cladding structure and the core design of PBG fibers indicate that it should be possible to tailor fibers with a number of new dispersion characteristics. Though the description of core design possibilities is beyond the scope of this paper, it should be noticed that the large modal index difference between the lower and the upper PBG boundaries offers room for new dispersion qualities.

Conclusion: It is possible to design optical fibers, not relying on total internal reflection as the guiding mechanism, exemplified by the Kagomé design introduced here. PBG fibers offer the possibility of making all-silica fibers, which may guide light in air. Also, it becomes possible to have fibers with group velocity dispersion quite different from standard optical fibers. At the conference a number of different cladding designs will be presented, along with a discussion of their basic qualities.

This work was supported by the Danish Technical Research Council under the THOR (Technology by Highly Oriented Research) program.

[1] E. Yablonovitch. Physical Review letters, 58(20):2059-62, May 1987.

[2] T.A. Birks, P.J. roberts, P. St. J. Russell, D.M. Atkin, and T.J. Shepherd. Electronics Letters, 31(22):1941-3, Oct. 1995.

[3] S.E. Barkou, J. Broeng, and A. Bjarklev. Optics letters, 21(19):1547-9, Jan 1999.

[4] J.C. Knight, J. Broeng, T.A. Birks, and P.St.J. Russell. Science, Vol.282, No.5393, 14761478,1998

[5] C.Domb, and M.S.Green. Phase Transitions and Critical Phenomena. Academic Press, 1972.

[6] A.A. Maradudin and A.R. McGurn. Journal of Modern Optics, 41(2):275-84, Feb. 1994

[7] J. Broeng, S.E. Barkou, A. Bjarklev, J.C. Knight, T.A. Birks, and P.St.J. Russell. Optics Communications, 156(4-6):240-4, Nov. 1998.

[8] D. Cassagne, C. Jouanin, and D. Bertho. Physical Review B, 53(11):7134-42, March 1996.

[9] J.D. Joannopoulos, J.N. Winn, and R.D. Meade. Photonic Crystals: Molding the Flow of Light. Princeton University Press, 1995.

[10] R.D. Meade, A.M. Rappe, K.D. Brommer, J.D. Joannopoulos, and O.L. Alerhand. Physical Review B, 48(11):8434-7, Sept. 1993

[11] S.E. Barkou, J. Broeng, and A. Bjarklev. OFC'99, FG5-1, San Diego, Feb. 1999.

[12] A. Bjarklev, J. Broeng, S. Barkou, and T. Søndergaard. Light for Life 99, Mexico. 